\title{
Predictive Role of CYFRA21-1 and CEA for Subsequent Docetaxel in Non-small Cell Lung Cancer Patients
}

\author{
KAZUKI SONE, TETSUYA OGURI, KEIMA ITO, YUKI KITAMURA, YOSHITSUGU INOUE, \\ AKIRA TAKEUCHI, SATOSHI FUKUDA, OSAMU TAKAKUWA, KEN MAENO, TAKAMITSU ASANO, \\ YOSHIHIRO KANEMITSU, HIROTSUGU OHKUBO, MASAYA TAKEMURA, YUTAKA ITO and AKIO NIIMI \\ Department of Respiratory Medicine, Allergy and Clinical Immunology, \\ Nagoya City University Graduate School of Medical Sciences, Nagoya, Japan
}

\begin{abstract}
Background/Aim: The aim of the present study was to determine the clinical value of tumor marker levels for previously treated NSCLC patients. Patients and Methods: We retrospectively screened 113 previously treated patients with advanced NSCLC who were treated with docetaxel monotherapy regarding the pretreatment serum level of cytokeratin 19 fragment (CYFRA21-1) and carcinoembryonic antigen (CEA). Results: The thirty-two patients with normal CYFRA21-1 levels and high CEA levels had a significantly higher response rate than the other 81 patients $(25 \%$ vs. $8.6 \%, p=0.031)$. The former group showed statistically longer progression-free survival (PFS) and overall survival (OS) than the latter group (median PFS, 180 vs. 59 days, $p<0.001$; median OS, 579 vs. 255 days, $p=0.002$ ). In multivariate analysis, tumor marker levels had a significant impact on PFS and OS. Conclusion: Combination of the two tumor markers is a predictive and prognostic marker of docetaxel monotherapy for previously treated NSCLC patients.
\end{abstract}

Docetaxel is one of the most widely used cytotoxic agents for non-small cell lung cancer (NSCLC). In particular, docetaxel monotherapy is one of the standard therapies for previously treated NSCLC patients (1). In the Japanese experience, the efficacy of low dose $\left(60 \mathrm{mg} / \mathrm{m}^{2}\right)$ docetaxel is in the same range as that of a dose of $75 \mathrm{mg} / \mathrm{m}^{2}$ (2). It was recently reported that docetaxel plus nadaplatin has a higher efficacy than the conventional standard regimen, docetaxel

Correspondence to: Tetsuya Oguri, Department of Respiratory Medicine, Allergy and Clinical Immunology, Nagoya City University Graduate School of Medical Sciences, 1 Kawasumi, Mizuho-cho, Mizuho-ku, Nagoya, Aichi, 467-8601, Japan. E-mail: t-oguri@med.nagoya-cu.ac.jp

Key Words: Cytokeratin 19 fragment, carcinoembryonic antigen, subsequent docetaxel, non-small cell lung cancer. plus cisplatin, in advanced lung squamous cell carcinoma patients (3). However, although docetaxel is currently an important drug for NSCLC, clinical predictive markers for the therapeutic effect of docetaxel have not been established.

Some tumor markers have prognostic significance (4). It was recently reported that CYFRA 21-1 is a predictive and prognostic marker for advanced NSCLC in a first line setting (5). Both serum carcinoembryonic antigen (CEA) and CYFRA 21-1 levels are widely used as tumor makers for NSCLC patients. However, no study has reported the predictive value of serum tumor markers for advanced NSCLC patients who were treated with docetaxel monotherapy in a second or a later line setting.

The aim of the present study was to analyze the predictive and prognostic value of pretreatment serum levels of CYFRA 21-1 and of CEA in patients with advanced-stage NSCLC who were treated with docetaxel monotherapy in a second- or a later-line setting.

\section{Patients and Methods}

In this retrospective cohort study, we screened for cases of advanced NSCLC patients who were treated with docetaxel monotherapy in a second- or later-line setting at Nagoya City University Hospital between 2005 and 2015. Approval for the study was obtained from our institutional ethics committee (no.1301), and routine medical data were analyzed under complete anonymity. All patients had locally advanced (stage IIIB) or metastasized (stage IV) NSCLC. Patients received docetaxel at a dose of 60 $\mathrm{mg} / \mathrm{m}^{2}$ on day 1 every 3 weeks.

Serum CYFRA 21-1 or CEA level was measured before the initial chemotherapy. The serum CYFRA 21-1 level was measured using a commercial electrochemiluminescence immunoassay on the LUMIPULSE Presto II system (Fujirebio Inc., Tokyo, Japan). The serum CEA level was measured using a commercial electrochemiluminescence immunoassay on the HISCL-5000 system (Sysmex, Hyogo, Japan). Measurements were made at laboratories in the Hospital, using cut-off values of $3.5 \mathrm{ng} / \mathrm{ml}$ for CYFRA 21-1, and $5.0 \mathrm{ng} / \mathrm{ml}$ for CEA, which were the upper limit of normal values in the hospital. 
Statistical analysis. Response rate (RR) was defined as the best overall RECIST response. Survival was estimated using the KaplanMeier method. Progression-free survival (PFS) was measured from the date of the first course of initial docetaxel chemotherapy to the date of first disease progression, of death or of the last follow-up. Overall survival (OS) was measured from the date of the first course of initial docetaxel chemotherapy to the date of death or of the last follow-up. Differences in RR between groups were evaluated using Fisher's exact test. A log-rank test was performed to evaluate the significance of differences in PFS and OS between the groups. As a level of statistical significance, $\alpha=0.05$ was used. Univariate analyses were done by means of log-rank tests. Multivariate analysis using a Cox proportional hazards model was used to establish the association between the clinical variables and survivals, and an $\alpha=0.05$ level of probability value was the significance level used for adding and deleting a co-variable from the model. As a level of statistical significance in the model, $\alpha=0.05$ was used. All statistical analyses were performed with EZR (Saitama Medical Center, Jichi Medical University, Saitama, Japan), which is a graphical user interface for R (The R Foundation for Statistical Computing, Vienna, Austria). More precisely, it is a modified version of $\mathrm{R}$ commander designed to add statistical functions frequently used in biostatistics (6).

\section{Results}

The study included 113 patients whose characteristics are shown in Table I. The median age was 67 years (range $=38$ 81 years). Thirty-one patients (27.4\%) were females, and 29 (25.7\%) were never smokers. Twenty-seven patients had squamous cell carcinoma, and 86 patients had non-squamous cell carcinoma (adenocarcinoma, large cell carcinoma and others). Most patients had stage IV disease; fifteen patients $(13.3 \%)$ had stage IIIB disease. Sixteen patients $(14.1 \%)$ had epidermal growth factor receptor (EGFR) mutation, and 3 patients $(2.7 \%)$ had anaplastic lymphoma kinase (ALK) translocation. No patient had both gene mutations. Of the 19 patients with EGFR mutation or ALK translocation, 15 patients had been treated with tyrosine kinase inhibitor (TKI) before docetaxel monotherapy. The median number of docetaxel monotherapy cycles was two.

Fifty-five (51.3\%) patients had a serum CYFRA 21-1 level that was above the normal upper limit of $3.5 \mathrm{ng} / \mathrm{ml}$ before the initial chemotherapy. The serum CEA level was elevated $(>5.0 \mathrm{ng} / \mathrm{ml})$ in $66(58.4 \%)$ patients before the initial docetaxel chemotherapy. Serum CYFRA 21-1 and CEA levels were not significantly correlated to histology (median CYFRA 21-1 level in non-squamous vs. squamous: 2.9 vs. $4.2 \mathrm{ng} / \mathrm{ml}$, Mann-Whitney $p=0.119$; median CEA level in non-squamous $v s$. squamous: $9.0 v s .4 .9$, MannWhitney $p=0.102)$. At the time of analysis, the median follow-up time was 299 days (range $=27-2805$ days). Patients with high CYFRA 21-1 levels tended to have a lower RR than patients with normal CYFRA 21-1 levels (7.3\% vs. $19.0 \%, p=0.095)$. There was no significant difference in RR between patients with high- and normal-CEA levels $(15.1 \%$
Table I. Patients characteristics ( $n=113)$.

\begin{tabular}{|c|c|}
\hline Characteristics & Value \\
\hline \multicolumn{2}{|l|}{ Age (years) } \\
\hline Median & 67 \\
\hline Range & $38-81$ \\
\hline \multicolumn{2}{|l|}{ Gender, $\mathrm{n}$} \\
\hline Male & 82 \\
\hline Female & 31 \\
\hline \multicolumn{2}{|l|}{ Smoking status, $\mathrm{n}$} \\
\hline Current or Former smoker & 84 \\
\hline Never smoked & 29 \\
\hline \multicolumn{2}{|l|}{ Histological type, $\mathrm{n}$} \\
\hline squamous cell carcinoma & 27 \\
\hline non-squamous cell carcinoma & 86 \\
\hline \multicolumn{2}{|l|}{ Disease stage, $\mathrm{n}$} \\
\hline IIIB & 15 \\
\hline IV & 98 \\
\hline \multicolumn{2}{|l|}{ Driver mutation status, $\mathrm{n}$} \\
\hline EGFR mutation & 16 \\
\hline ALK translocation & 3 \\
\hline negative or unknown & 94 \\
\hline \multicolumn{2}{|l|}{ No. of prior systemic regimens, $n$} \\
\hline 1 & 65 \\
\hline$>2$ & 48 \\
\hline \multicolumn{2}{|l|}{ Prior platinum drug therapy, $\mathrm{n}$} \\
\hline Yes & 105 \\
\hline No & 8 \\
\hline \multicolumn{2}{|l|}{ No. of docetaxel cycles } \\
\hline Median & 2 \\
\hline Range & $1-28$ \\
\hline \multicolumn{2}{|l|}{ Serum CEA level (ng/ml) } \\
\hline Median & 6.8 \\
\hline Range & $1.2-18215$ \\
\hline \multicolumn{2}{|l|}{ Serum CYFRA 21-1 level (ng/ml) } \\
\hline Median & 3.8 \\
\hline Range & $0.5-214.0$ \\
\hline
\end{tabular}

EGFR, Epidermal growth facter receptor; ALK, anaplastic lymphoma kinase; CEA, carcinoembryonic antigen; CYFRA 21-1, cytokeratin 19 fragment.

vs. $10.6 \%, p=0.581$ ). Patients with high levels of CYFRA 21-1 also experienced statistically shorter PFS compared with those with normal levels of CYFRA 21-1 (log-rank $p<0.001)$. The median PFS was 62 days $(95 \%$ confidence interval $(\mathrm{CI})=47-81$ days) for patients with high levels of CYFRA 21-1 and 111 days (95\% CI=70-168 days) for those with normal levels of CYFRA 21-1 (Figure 1-A1). The median duration of PFS of patients with high serum CEA levels tended to be longer than that of patients with normal serum CEA levels (102 days (95\% CI=61-166 days) vs. 57 days (95\% CI $=43-81$ days), respectively; $(p=0.057)$ ) (Figure 1-B1). As shown in Figure 1-A2, the median duration of OS in patients with high- and normal- levels of CYFRA 21-1 was 219 days $(95 \% \mathrm{CI}=140-298$ days $)$ and 408 days (95\% CI=314-531 days), respectively $(p<0.001)$. The median 

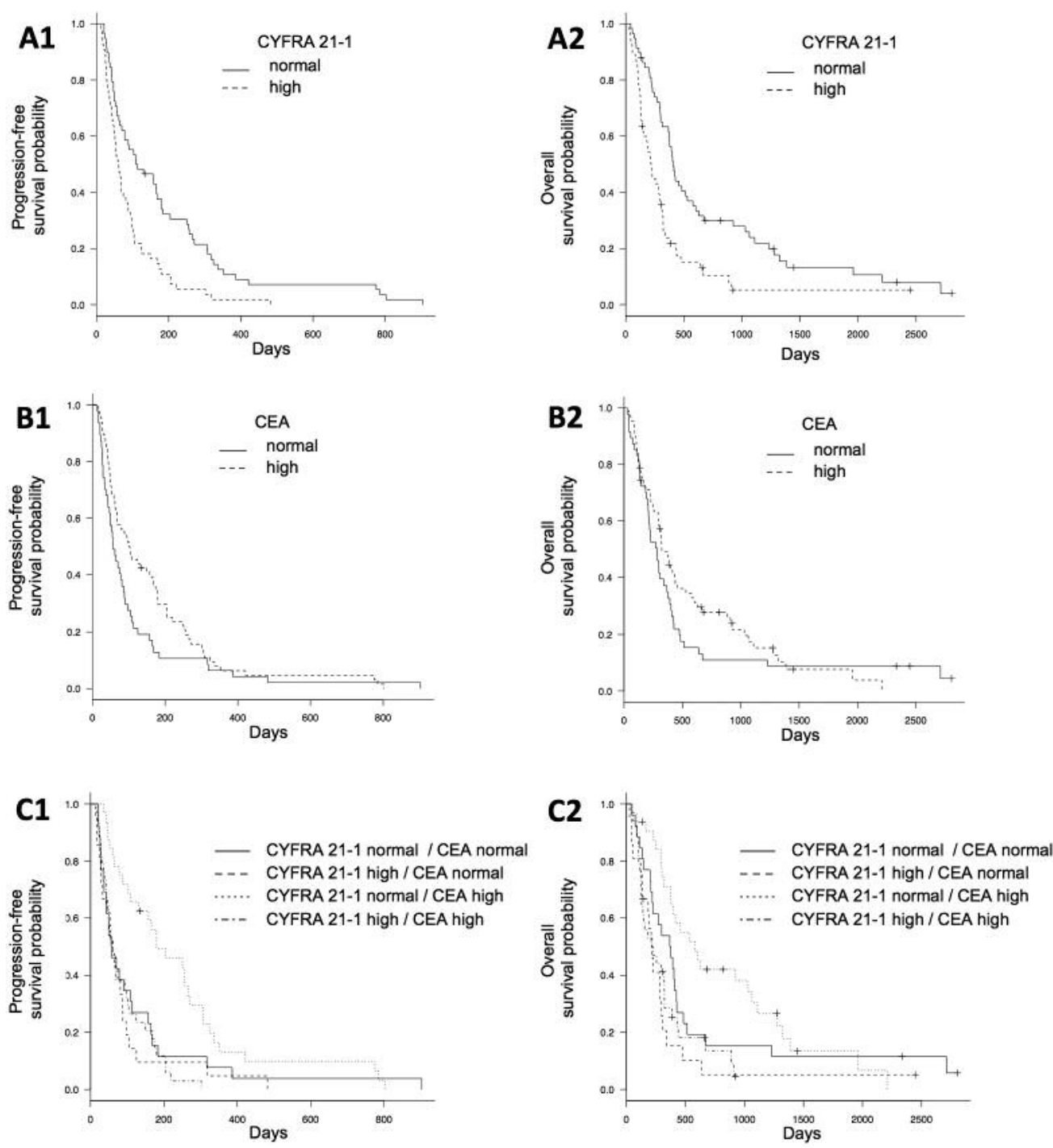

Figure 1. Kaplan-Meier survival curves of progression-free survival (PFS) and overall survival (OS) according to serum cytokeratin 19 fragment (CYFRA 21-1) levels (A1, A2), serum carcinoembryonic antigen (CEA) levels (B1, B2) or combined evaluation of both tumor markers (C1, C2). The median PFS in patients with high-and normal- serum CYFRA 21-1 levels was 62 days (95\% confidence interval (CI), $47-81$ days) and 111 days (95\%CI=70-168 days), respectively $(p<0.001)$. The median OS in patients with high-and normal- levels of CYFRA $21-1$ was 219 days (95\%CI=140-298 days) and 408 days $(95 \% C I=314-531$ days), respectively $(p<0.001)$. The median PFS in patients with high-and normal-serum $C E A$ levels was 102 days (95\% CI=62-166 days) and 57 days (95\%CI, 43-81 days), respectively ( $p=0.057)$. The median OS in patients with highand normal- levels of CEA was 323 days (95\%CI=291-439 days) and 284 days (95\%CI=207-368 days), respectively ( $p=0.264)$. The median PFS in patients with normal CYFRA levels and high CEA levels and that in the other patients was 180 days (95\%CI=103-266 days) and 59 days (95\% CI=49-74 days), respectively $(p<0.001)$. The median OS in patients with normal CYFRA levels and high CEA levels and that in the other patients was 579 days (95\% CI, 374-1064 days) and 255 days (95\%CI=201-318 days), respectively ( $p=0.002)$.

duration of OS of patients with high- and normal- serum CEA levels was 323 days ( $95 \% \mathrm{CI}=291-439$ days) and 284 days $(95 \% \mathrm{CI}=207-368$ days), respectively $(p=0.264)$ (Figure 1-B2). As described above, a normal CYFRA 21-1 level and a high CEA level tended to lead to a good prognosis. We therefore compared patients with normal CYFRA 21-1 and high CEA levels with the other patients (those with high
CYFRA 21-1 levels or normal CEA levels). Patients with normal CYFRA 21-1 levels and high CEA levels had a significantly higher RR than the other patients $(25 \%$ vs. $8.6 \%, p=0.031$ ). Patients with normal CYFRA 21-1 levels and high CEA levels experienced statically longer PFS and OS than the other patients (median PFS: 180 days $v s .59$ days, $p<0.001$; median OS: 579 days $v s .255$ days, $p=0.002$ ) 
Table II. Univariate analysis of survival by the log-rank test.

\begin{tabular}{|c|c|c|c|c|c|}
\hline Factor & $\mathrm{n}$ & Median PFS (days) & $p$-Value & Median OS (days) & $p$-Value \\
\hline Age & & & 0.5 & & 0.219 \\
\hline$\geq 70$ & 69 & 78 & & 340 & \\
\hline$<70$ & 44 & 71 & & 296 & \\
\hline Gender & & & 0.038 & & 0.011 \\
\hline Men & 82 & 69 & & 296 & \\
\hline Women & 31 & 104 & & 439 & \\
\hline Smoking status & & & 0.007 & & 0.011 \\
\hline Never smoked & 29 & 149 & & 458 & \\
\hline Current or Former smoker & 84 & 66 & & 292 & \\
\hline Histology & & & 0.430 & & 0.646 \\
\hline non-squamous cell & 86 & 83 & & 322 & \\
\hline squamous cell & 27 & 53 & & 286 & \\
\hline No. of prior systemic regimens & & & 0.340 & & 0.883 \\
\hline 1 & 65 & 62 & & 296 & \\
\hline $2<$ & 48 & 97 & & 374 & \\
\hline Response to 1 st line chemotherapy & & & 0.016 & & $<0.001$ \\
\hline not PD & 88 & 84 & & 368 & \\
\hline $\mathrm{PD}$ & 25 & 69 & & 154 & \\
\hline Serum CYFRA 21-1 levels & & & $<0.001$ & & $<0.001$ \\
\hline$\leq 3.5 \mathrm{ng} / \mathrm{ml}$ & 58 & 111 & & 408 & \\
\hline$>3.5 \mathrm{ng} / \mathrm{ml}$ & 55 & 62 & & 219 & \\
\hline Serum CEA levels & & & 0.057 & & 0.264 \\
\hline$\leq 5.0 \mathrm{ng} / \mathrm{ml}$ & 47 & 57 & & 284 & \\
\hline$>5.0 \mathrm{ng} / \mathrm{ml}$ & 66 & 102 & & 323 & \\
\hline Serum CYFRA 21-1 and CEA levels & & & $<0.001$ & & 0.002 \\
\hline CYFRA $21-1 \leq 3.5 \mathrm{ng} / \mathrm{ml}$ and CEA $>5.0 \mathrm{ng} / \mathrm{ml}$ & 32 & 180 & & 579 & \\
\hline CYFRA $21-1>3.5 \mathrm{ng} / \mathrm{ml}$ or CEA $\leq 5.0 \mathrm{ng} / \mathrm{ml}$ & 81 & 59 & & 255 & \\
\hline
\end{tabular}

PFS, Progression-free survival; OS, overall survival; PD, progression disease; CYFRA 21-1, cytokeratin 19 fragment; CEA, carcinoembryonic antigen.

(Figure 1-C1, C2). To determine potential predictive and prognostic factors among clinical characteristics including the serum CYFRA 21-1/CEA level in the previously treated NSCLC patients who were treated with docetaxel monotherapy, we performed a univariate analysis of the clinical variables listed in Table II. The factors of 'disease stage' and 'driver mutation status' were excluded from this analysis because they were too one-sided (one-side was smaller than 20). Sex, smoking status, response to first line chemotherapy, and CYFRA 21-1/CEA levels were associated with both PFS and OS (Table II). To determine independent prognostic factors, we performed multivariate analyses (Table III). A normal CYFRA 21-1 level and a high CEA level was statically associated with longer PFS (Hazard ratio $(\mathrm{HR})=0.48 ; 95 \% \mathrm{CI}=0.31-0.75 ; p=0.001)$ and $\mathrm{OS}(\mathrm{HR}=0.52$; $95 \% \mathrm{CI}=0.31-0.88 ; p=0.015)$.

\section{Discussion}

This study showed that combination of normal serum levels of CYFRA 21-1 and high serum levels of CEA before docetaxel monotherapy was associated with higher RR and longer PFS and OS in previously treated patients with advanced NSCLC. The duration of both PFS and OS correlated with normal serum CYFRA 21-1 and high serum CEA levels in multivariate analysis.

Past studies have reported that $\beta$-tubulin III expression in the tumor (7), a genetic variant of cytochrome P450 1B1 (8), STMN1 gene polymorphism (9) or a polymorphism of genes encoding multidrug resistance protein (10) were predictive markers for docetaxel chemotherapy in NSCLC. However, it is difficult to measure those markers in the clinical setting. The response to previous chemotherapy was reported to have predictive value in relation to subsequent docetaxel therapy (11). However, the predictive value of this response did not have sufficient capacity for the selection of patients who would benefit from docetaxel therapy.

In previous studies, a pretreatment high serum CYFRA 21-1 level was reported to be related to shorter PFS and OS for first-line chemotherapies in advanced-stage NSCLC patients (5). In the present study, a high CYFRA 21-1 level was also related to a worse prognosis for docetaxel monotherapy in previously treated patients. On the other hand, this is the first report that high CEA levels were 
Table III. Multivariate analysis of survival using a Cox proportional hazards model.

\begin{tabular}{|c|c|c|c|c|}
\hline \multirow[b]{2}{*}{ Factor } & \multicolumn{2}{|c|}{ PFS } & \multicolumn{2}{|c|}{ OS } \\
\hline & $\mathrm{HR}(95 \% \mathrm{CI})$ & $p$-Value & $\mathrm{HR}(95 \% \mathrm{CI})$ & $p$-Value \\
\hline Gender & & 0.853 & & 0.104 \\
\hline Men & 1.00 & & 1.00 & \\
\hline Women & $0.93(0.42-2.06)$ & & $0.58(0.30-1.12)$ & \\
\hline Smoking status & & 0.399 & & 0.973 \\
\hline Never smoked & 1.00 & & 1.00 & \\
\hline Current or Former smoker & $1.42(0.62-3.24)$ & & $0.98(0.49-2.00)$ & \\
\hline Response to 1 st line chemotherapy & & 0.281 & & 0.735 \\
\hline not PD & 1.00 & & 1.00 & \\
\hline $\mathrm{PD}$ & $1.24(0.84-1.86)$ & & $0.93(0.62-1.40)$ & \\
\hline Serum CYFRA 21-1 and CEA levels & & 0.001 & & 0.015 \\
\hline CYFRA $21-1>3.5 \mathrm{ng} / \mathrm{ml}$ or CEA $\leq 5.0 \mathrm{ng} / \mathrm{ml}$ & 1.00 & & 1.00 & \\
\hline CYFRA $21-1 \leq 3.5 \mathrm{ng} / \mathrm{ml}$ and CEA $>5.0 \mathrm{ng} / \mathrm{ml}$ & $0.48(0.31-0.75)$ & & $0.52(0.31-0.88)$ & \\
\hline
\end{tabular}

HR, Hazard ratio; CI, confidence interval; PFS, progression-free survival; OS, overall survival; PD, progression disease; CYFRA 21-1, cytokeratin 19 fragment; CEA, carcinoembryonic antigen.

associated with a good prognosis in cytotoxic chemotherapy for NSCLC. Past studies showed that high serum CEA levels predicted a good response to EGFR tyrosine kinase inhibitors (12). As for docetaxel monotherapy, it was reported that a non-squamous cell histology was associated with higher RR and longer PFS (13). CEA is a specific tumor marker of adenocarcinoma, which accounts for a large portion of nonsquamous cell cancer. Similarly, CYFRA 21-1 is specific for squamous carcinoma. Although histology was not related to the efficacy of docetaxel in this study, combined evaluation of the serum CEA and CYFRA 21-1 levels may be a more specific marker for the adenocarcinoma component, considering that pathogenic diagnosis of advanced NSCLC has been shown to involve many false-positives/-negatives due to small biopsies (14).

In general, high tumor marker levels are considered to lead to a worse outcome through tumor burden. Indeed, a preoperative high serum CYFRA 21-1 and CEA level was associated with poor survival in operated early stage NSCLC patients (15). In contrast, patients with high pretreatment CEA levels experienced better outcome in this study. Therefore, there is a possibility that pretreatment tumor marker levels reflect tumor properties in advanced NSCLC patients. In basic studies, it was reported that caspase 3 cleaves full length cytokeratin 19 in the apoptotic phase, and that the cytokeratin 19 fragment (CYFRA 21-1) thus generated is released to the extracellular space (16). Moreover, it was shown that caspase 3 mediates angiogenesis through vascular endothelial growth factor (VEGF) (17). It is known that a high level of VEGF leads to a worse outcome $(18,19)$. Taking these findings into consideration, a high level of CYFRA 21-1 may be related to shorter survival through a high level of VEGF. Further research, such as a xenograft model (20), to investigate the mechanism how tumor marker levels reflect their properties, is expected. On the other hand, it was recently reported that docetaxel plus an anti-angiogenic agent (bevacizumab or ramcirumab) is more efficient than docetaxel monotherapy in a second-line setting (21). The addition of an anti-angiogenic agent to docetaxel may be a better treatment strategy for previously treated NSCLC patients with high CYFRA 21-1 levels. Further study that investigates the difference in efficacy of an anti-angiogenic agent according to patient tumor marker profiles is expected.

The major limitation of the present study is that it is based on retrospective analysis of patients in a single institute. There may be a potential bias with regard to patient selection and follow-up procedures. However, in this study, we demonstrated both the predictive and prognostic role of CYFRA 21-1 and CEA for subsequent docetaxel in multivariate analysis. Therefore, we believe that this result is reliable. To validate this, further prospective studies to investigate different efficacy of docetaxel according to pretreatment tumor marker levels are needed. In addition, it is necessary to examine the cut-off point of serum tumor markers from the viewpoint of predictive or prognostic value. However, the cut-off point that we adopted was the upper limit of normal values, and this cut-off point was effective for estimating prognosis. Therefore, we consider that this cut-off point is also appropriate in the viewpoint of predictive or diagnostic value. 
In conclusion, our study suggests that the serum level of CYFRA 21-1 and CEA before treatment is a predictive and prognostic factor of docetaxel monotherapy in previously treated NSCLC patients. This result is expected to be helpful for the selection of patients with advanced NSCLC who can benefit from subsequent docetaxel therapy. Recently, immunocheckpoint inhibitors were also reported to be more efficient for previously treated NSCLC patients than docetaxel monotherapy $(22,23)$. Further investigation, in terms of decisions regarding NSCLC patient treatment according to the pretreatment serum levels of CYFRA 21-1 and CEA may be of value.

\section{References}

1 Fossella FV, DeVore R, Kerr RN, Crawford J, Natale RR, Dunphy F, Kalman L, Miller V, Lee JS, Moore M, Gandara D, Karp D, Vokes E, Kris M, Kim Y, Gamza F and Hammershaimb L: Randomized phase iii trial of docetaxel versus vinorelbine or ifosfamide in patients with advanced non-small-cell lung cancer previously treated with platinum-containing chemotherapy regimens. The tax 320 non-small cell lung cancer study group. J Clin Oncol 18(12): 2354-2362, 2000.

2 Mukohara T, Takeda K, Miyazaki M, Takifuji N, Terakawa K and Negoro S: Japanese experience with second-line chemotherapy with low-dose $\left(60 \mathrm{mg} / \mathrm{m}^{2}\right)$ docetaxel in patients with advanced non-small-cell lung cancer. Cancer Chemother Pharmacol 48(5): 356-360, 2001.

3 Shukuya T, Yamanaka T, Seto T, Daga H, Goto K, Saka H, Sugawara S, Takahashi T, Yokota S, Kaneda H, Kawaguchi T, Nagase S, Oguri T, Iwamoto $Y$, Nishimura T, Hattori $Y$, Nakagawa K, Nakanishi Y and Yamamoto N: Nedaplatin plus docetaxel versus cisplatin plus docetaxel for advanced or relapsed squamous cell carcinoma of the lung (wjog52081): A randomised, open-label, phase 3 trial. Lancet Oncol 16(16): 1630-1638, 2015.

4 Agnantis NJ, Goussia AC, Batistatou A and Stefanou D: Tumor markers in cancer patients. An update of their prognostic significance. Part ii. In Vivo 18(4): 481-488, 2004.

5 Sone K, Oguri T, Nakao M, Kagawa Y, Kurowaka R, Furuta H, Fukuda S, Uemura T, Takakuwa O, Kanemitsu Y, Ohkubo H, Takemura M, Maeno K, Ito Y, Sato H, Muramatsu H and Niimi A: Cyfra 21-1 as a predictive marker for non-small cell lung cancer treated with pemetrexed-based chemotherapy. Anticancer Res 37(2): 935-939, 2017.

6 Kanda Y: Investigation of the freely available easy-to-use software 'ezr' for medical statistics. Bone Marrow Transplant 48(3): 452-458, 2013.

7 Hayashi Y, Kuriyama H, Umezu H, Tanaka J, Yoshimasu T, Furukawa T, Tanaka H, Kagamu H, Gejyo F and Yoshizawa H: Class iii beta-tubulin expression in tumor cells is correlated with resistance to docetaxel in patients with completely resected nonsmall-cell lung cancer. Intern Med 48(4): 203-208, 2009.

8 Vasile E, Tibaldi C, Leon GL, D'Incecco A and Giovannetti E: Cytochrome p450 1b1 (cyp1b1) polymorphisms are associated with clinical outcome of docetaxel in non-small cell lung cancer (nsclc) patients. J Cancer Res Clin Oncol 141(7): 1189-1194, 2015.
9 Powrozek T, Mlak R, Krawczyk P, Barton S, Biernacka B, Malecka-Massalska T and Milanowski J: Retrospective analysis of second-line chemotherapy outcomes with paclitaxel or docetaxel in correlation with stmn 1 polymorphism in advanced non-small cell lung cancer patients. Clin Transl Oncol 18(1): 3339, 2016.

10 Szczyrek M, Mlak R, Krawczyk P, Wojas-Krawczyk K, Powrozek T, Szudy-Szczyrek A, Zwolak A, Daniluk J and Milanowski J: Polymorphisms of genes encoding multidrug resistance proteins as a predictive factor for second-line docetaxel therapy in advanced non-small cell lung cancer. Pathol Oncol Res 23(3): 607-614, 2016.

11 Goto Y, Sekine I, Yamada K, Nokihara H, Yamamoto N, Kunitoh $\mathrm{H}$, Ohe $\mathrm{Y}$ and Tamura $\mathrm{T}$ : Influence of previous chemotherapy on the efficacy of subsequent docetaxel therapy in advanced non-small cell lung cancer patients. J Thorac Oncol 3(4): 412-416, 2008.

12 Okamoto T, Nakamura T, Ikeda J, Maruyama R, Shoji F, Miyake $\mathrm{T}$, Wataya $\mathrm{H}$ and Ichinose $\mathrm{Y}$ : Serum carcinoembryonic antigen as a predictive marker for sensitivity to gefitinib in advanced non-small cell lung cancer. Eur J Cancer 41(9): 1286-1290, 2005.

13 Miura S, Murakami H, Tamiya A, Morii S, Akamatsu H, Ono A, Syukuya T, Kenmotsu H, Tsuya A, Nakamura Y, Kaira K, Naito $\mathrm{T}$, Takahashi $\mathrm{T}$, Endo $\mathrm{M}$, Nakajima $\mathrm{T}$ and Yamamoto $\mathrm{N}$ : Differential efficacy of docetaxel according to non-small cell lung cancer histology and the therapeutic effect of epidermal growth factor receptor tyrosine kinase inhibitors. Oncol Lett 2(6): 1059-1064, 2011.

14 Cataluna JJ, Perpina M, Greses JV, Calvo V, Padilla JD and Paris F: Cell type accuracy of bronchial biopsy specimens in primary lung cancer. Chest 109(5): 1199-1203, 1996.

15 Muley T, Dienemann H and Ebert W: Cyfra 21-1 and cea are independent prognostic factors in 153 operated stage i nsclc patients. Anticancer Res 24(3b): 1953-1956, 2004.

16 Dohmoto K, Hojo S, Fujita J, Yang Y, Ueda Y, Bandoh S, Yamaji Y, Ohtsuki Y, Dobashi N, Ishida T and Takahara J: The role of caspase 3 in producing cytokeratin 19 fragment (cyfra21-1) in human lung cancer cell lines. Int J Cancer 91(4): 468-473, 2001.

17 Feng X, Tian L, Zhang Z, Yu Y, Cheng J, Gong Y, Li CY and Huang Q: Caspase 3 in dying tumor cells mediates postirradiation angiogenesis. Oncotarget 6(32): 32353-32367, 2015.

18 Gkiozos I, Tsagouli S, Charpidou A, Grapsa D, Kainis E, Gratziou C and Syrigos K: Levels of vascular endothelial growth factor in serum and pleural fluid are independent predictors of survival in advanced non-small cell lung cancer: Results of a prospective study. Anticancer Res 35(2): 1129-1137, 2015.

19 Affara NI and Robertson FM: Vascular endothelial growth factor as a survival factor in tumor-associated angiogenesis. In Vivo 18(5): 525-542, 2004.

20 Bak M Jr., Mattern J and Volm M: Maintenance of morphology and tumour marker production in human epidermoid lung carcinoma xenografts. In Vivo 1(5): 319-326, 1987.

21 Garon EB, Ciuleanu TE, Arrieta O, Prabhash K, Syrigos KN, Goksel T, Park K, Gorbunova V, Kowalyszyn RD, Pikiel J, Czyzewicz G, Orlov SV, Lewanski CR, Thomas M, Bidoli P, Dakhil S, Gans S, Kim JH, Grigorescu A, Karaseva N, Reck M, Cappuzzo F, Alexandris E, Sashegyi A, Yurasov S and Perol M: 
Ramucirumab plus docetaxel versus placebo plus docetaxel for second-line treatment of stage iv non-small-cell lung cancer after disease progression on platinum-based therapy (revel): A multicentre, double-blind, randomised phase 3 trial. Lancet 384(9944): 665-673, 2014.

22 Brahmer J, Reckamp KL, Baas P, Crino L, Eberhardt WE, Poddubskaya E, Antonia S, Pluzanski A, Vokes EE, Holgado E, Waterhouse D, Ready N, Gainor J, Aren Frontera O, Havel L, Steins M, Garassino MC, Aerts JG, Domine M, Paz-Ares L, Reck M, Baudelet C, Harbison CT, Lestini B and Spigel DR: Nivolumab versus docetaxel in advanced squamous-cell non-small-cell lung cancer. N Engl J Med 373(2): 123-135, 2015 .
23 Borghaei H, Paz-Ares L, Horn L, Spigel DR, Steins M, Ready NE, Chow LQ, Vokes EE, Felip E, Holgado E, Barlesi F, Kohlhaufl M, Arrieta O, Burgio MA, Fayette J, Lena H, Poddubskaya E, Gerber DE, Gettinger SN, Rudin CM, Rizvi N, Crino L, Blumenschein GR Jr., Antonia SJ, Dorange C, Harbison $\mathrm{CT}$, Graf Finckenstein $\mathrm{F}$ and Brahmer JR: Nivolumab versus docetaxel in advanced nonsquamous non-small-cell lung cancer. N Engl J Med 373(17): 1627-1639, 2015.

Received June 20, 2017

Revised July 7, 2017

Accepted July 14, 2017 